\title{
Molecular Docking, ADMET Analysis and Dynamics Approach to Potent Natural Inhibitors against Sex Hormone Binding Globulin in Male Infertility
}

\author{
Morvin Yabesh Jobu Esther*, Vijayakumar Subramaniyan, Arulmozhi Praveen Kumar, \\ Mahadevan Subramanian and Manogar Palani
}

\section{Morvin Yabesh Jobu Esther*, Vijayakumar Subramaniyan, Arulmozhi Praveen Kumar, Mahadevan Subramanian and Manogar Palani}

Computational Phytochemistry Lab, $P G$ and Research Department of Botany and Microbiology, AVVM Sri Pushpam College (Autonomous) Poondi, Thanjavur (Dist), Tamil Nadu, India

\section{Correspondence}

Morvin yabesh Jobu Esther

Computational Phytochemistry Lab, PG and Research Department of Botany and Microbiology, AVVM Sri Pushpam College (Autonomous) Poondi, Thanjavur (Dist),

Tamil Nadu, India

Phone no: 09003311921

E-mail: svijaya_kumar2579@rediff.com

\section{History}

- Submission Date: 18-10-2017;

- Review completed: 31-07-2017;

- Accepted Date: 14-11-2017

DOI : 10.5530/pj.2017.6s.155

Article Available online

http://www.phcogj.com/v9/i6s

\section{Copyright}

(C) 2017 Phcog.Net. This is an openaccess article distributed under the terms of the Creative Commons Attribution 4.0 International license.

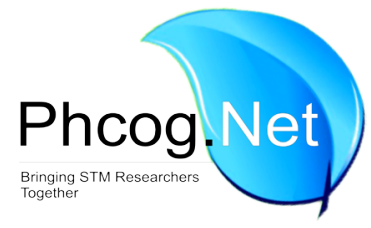

\begin{abstract}
Objectives: The Sex Hormone Binding Globulin (SHBG) plays an important role in male infertility. Methods: The present research computationally emphases to SHBG protein with 47 natural phytocompounds using docking studies. Results: From the results showed the interactions between $1 \mathrm{KDM}$ protein with 47 phytocompounds, a natural compound chlorogenic acid showed the best glide docking XP score $-7.255 \mathrm{kcal} / \mathrm{mol}$ and the binding energy value of $-47.869 \mathrm{kcal} /$ $\mathrm{mol}$. Based on the result, the chlorogenic acid and target were run on MD simulations stable at 10 ns. Conclusion: Finally, this study concludes the chlorogenic acid is a suitable drug candidate for infertility.

Key words: Male infertility, SHBG, Phytocompounds, Molecular docking, ADMET property, MD simulations.
\end{abstract}

\section{INTRODUCTION}

Infertility is a disease of the reproductive system which affects both men and women with practically parallel recurrence. It is a global phenomenon affecting an average of $10 \%$ of human reproductive age population. ${ }^{1}$ Male infertility is affecting one in six couple in common ${ }^{2}$ which interferes with the process of spermatogenesis and reduce sperm quality and quantity. Mostly, men are affecting this infertility disease due to coronary heart diseases, diabetes mellitus, chronic liver diseases, chronic smoking, and insufficient vitamins, few genetic factor intakes have been reported to cause deleterious effects on spermatogenesis. ${ }^{3}$ Androgens plays a central role in the maintenance of normal spermatogenesis, if androgen levels are decreased, infertility could ensue. Gonadotropins [luteinizing hormone (LH) and follicle stimulating hormone (FSH)] secretion of estrogen reduces at pituitary level resulting in decreased testicular function and reduction in testosterone production and intratesticular and serum testosterone levels. The balance between serum androgen and estrogens is essential for normal semen parameters. ${ }^{4,5}$ There are few specify information about Sex hormonebinding globulin (SHBG) is a high molecular weight plasma protein that binds androgens and estrogens and plays a key role in maintaining the balance between unbound and bound sex steroids. ${ }^{6}$

If we consider deeper high -binding affinity, SHBG acts as a major part of steroids in the blood and any changes in SHBG levels effects the allocation and entrance of these molecules to target tissues. Besides natural steroid hormones such as dihydrotestosterone, testosterone, and estradiol, SHBG has also been shown to bind several EDCs including phthalates esters. Binding of the endocrine disrupting chemicals such as phthalate esters to SHBG in the body represents a potential way of interfering in the natural ligand and protein interactions and leads to harmful effect for the usual performance of the steroid target organs. Molecular modeling of zebra fish homolog of SHBG with several EDCs has been reported. In recent years, reported docking of many phthalates with androgen, progesterone, estrogen and peroxisome proliferating-activated receptors (PPARs). However, molecular modeling studies of phthalate esters with human SHBG are apparently not available. These are the information's about the infertility disease. ${ }^{7,8,9}$

\section{MATERIALS AND METHODS}

Molecular study was performed using different modules of Schrodinger. ${ }^{10}$ The schematic representation describes the work flow of the study Figure 1 followed by detailed description in the subsequent sections.

\section{Modeling platform}

All computational analysis was carried out on Schrodinger suite device Maestro 10.2 version (ligprep, glide XP docking, grid genera- 
tion, free energy calculations, and ADME-toxicity and MD simulations). This software package programmed on DELL PRECISSION T1700 workstation machine running on Intel (R) Core (TM) i5-4590 CPU processor with 8GB RAM and 240 GB hard disk with centos Linux as the operating system. The schematic representation describes the work flow of the study followed by detailed description in the subsequent sections. ${ }^{11}$

\section{Biological data}

In this study 47 bioactive molecules were selected against the target of SHBG. These bioactive molecules names and their medicinal plants were linsted in Table $1 .{ }^{12-31}$ Later, this collected 47 bioactive molecules were retrieved from the chemical database. ${ }^{32}$ The sex hormone-binding globulin (SHBG) receptor was obtained from Protein Data Bank PDB ID: $1 \mathrm{KDM}^{33}$

\section{Preprocessing and preparation of protein target structure}

Protein X-ray crystal structures of SHBG was obtained from the Protein Data Bank after converted into PDB format with the help of Schrodinger software. The protein preparation is using by the tool of protein preparation wizard on Schrodinger suite. In general, protein is commonly occupied the water molecules. But, this process was evacuating those water molecules for increasing the entropy of target. ${ }^{34,35}$

\section{Preprocessing and preparation of ligands}

All the ligand molecules are prepared by the tool ligprep in Schrodinger. ${ }^{36}$ Later these ligand molecules optimized on various ionization states, tautomer, stereo chemistries and ring conformations to adding molecules. It was using ligand rotatable bonds can move freely on further process. ${ }^{37,38}$

\section{Molecular docking analysis}

The Maestro suite ${ }^{10}$ was used to perform molecular docking and utilized to prepare the input pdb file SHBG (PDB ID: $1 \mathrm{KDM}$ ). Molecular docking uses the computational simultion predicts the ligand preferred orientation to a receptor when interact each other to form a higher stability complex. In this study Maestro 10.2 version tool was used to perform rigid flexible docking for predicting binding affinity, ligand efficiency and inhibitory constant. Glide Extra precision (XP) tool is used for the justification of suitable ligand molecule to the active site of specific target. The ligands being docked were kept flexible. . $^{39,40}$

\section{Molecular dynamics simulations}

MD simulation was performed using Macromodel Version9.0 (a Schrodinger module). ${ }^{41}$ The OPLS_2005 force field was used for the energy calculation. Constant temperature was $300 \mathrm{~K}$ and in the integration step 1.0 fs was given. Run the MD simulations for complex structure. MD simulation with position restraints was carried out for a period of 4000 PS to allow the accommodation of the water molecules in the system. Finally, Root Mean Square Deviation (RMSD) was calculated for checking the stability of $1 \mathrm{KDM}$ protein with their native motion. All the coordinate file was saved every 1000 ps upto 4 ns and the result was analyzed by Scatter Plot. ${ }^{42-44}$

\section{Estimation of ligand binding energy using Prime-MM-GBSA}

The ligand binding energy of total 10 phytocompounds to inhibit SHBG was estimated using Prime MM-GBSA module in Schrodinger Suite $2014{ }^{45}$ The total free energy of binding, dGbind ( $\left.\mathrm{kcal} / \mathrm{mol}\right)$ is estimated by the software as:

$$
\Delta \mathrm{G} \text { bind }=\mathrm{G} \text { complex }-(\mathrm{G} \text { protein }+\mathrm{G} \text { ligand })
$$

Where in each energy term is a combination of $\mathrm{G}=\mathrm{MME}$ (molecular mechanics energies) + GSGB (SGB solvation model for polar solvation)
+ GNP (nonpolar solvation) Coulomb energy, Covalent binding energy, Van der Waals energy, Lipophilic energy, Generalized Born electrostatic solvation energy, Prime energy, Hydrogen-bonding energy, Pi-pi packing energy, Self-contact correction. ${ }^{46}$ We then used this score to rank the ligand-protein glide XP docked complex. ${ }^{47}$

\section{ADME-Toxicity}

ADMET (absorption, distribution, metabolism, excretion and toxicity) predictions for the top docking hits (47 natural bioactive compounds) were calculated by using the QikProp ${ }^{48}$ module of Schrodinger suite (QikProp, version 3.0, Schrodinger, LLC, New York, NY, 2010) program (Schrödinger software) running in normal mode. QikProp generates physically relevant descriptors, the toxicity a ligand is considered important for the ligand to act as an effectual drug discovery of new drug development. These entire processes were used by Schrodinger software. ${ }^{49}$

\section{RESULTS}

\section{Molecular docking}

In this study, we intended to explore the overlaps SHBG inhibitory special effects of chlorogenic acid. In this protein sequence length is 177 amino acids and the resolution is $2.35 \AA$. These structures were to abolish water elements. A descriptive hydrogen atom was added to every inhibitor to assure that all of them were all-atom structures followed by energy minimization. After the protein preparation process is over, the protein is ready going with molecular docking. This molecular docking analysis has shown drug molecules potential and their hydrogen bond interaction where from the binding site of target. A total number of 10 natural compounds molecules in complex with SHBG protein were docked. Each ligand was docked with SHBG receptor that ligand molecules were produced docking score. The H-bond distance and their consequent glide energy were generated. And leading the docking score better drug for target molecules. ${ }^{50}$ Based on the research finding which molecule is placed leading docking score with the good binding affinities. We justified, it is a suitable ligand for target.

In this analysis, a natural compound of chlorogenic acid has shown better results than other molecules. On the other hand, chlorogenic acid is a flavonoid nature. Moreover, this molecule is solving the male infertility problems and it was tested in both chemically and computationally. ${ }^{51}$ This analysis outcome many compounds have received the docking score more than -4.0 Table 2 . But, chlorogenic acid is received maximum value of docking score-7.225. Table 2.

\section{Molecular interactions of chlorogenic acid with functionally important residues of SHBG}

The SHBG protein interactions with ligands surfaces are controlled by a complex array of intermolecular interaction. Such interactions depend both on the specific interactions in the binding site as well as the nonspecific forces outside the binding pocket. The protein- ligand interaction pattern between SHBG and chlorogenic acid was examined the site to which chlorogenic acid was binding. The chlorogenic acid was robustly interacting with diverse residues of the hydrogen bond (Side-chain, Back-chain) SER 180, TRP 170, SER 169, and ASP 168. In this interaction ASP 168 residues is involved in two times and the LYS 173 also interact n-cation Figure 2.

\section{Analysis of docking results}

The results of our docking analysis, pertaining to each ligand is presented below. The docking scores and binding affinities are presented in Table 2.

\section{Chlorogenic acid}

Through our molecular docking experiment, we found that chlorogenic acid efficiency. As a result chlorogenic acid had the best Glide Gscore 
$(-7.255 \mathrm{kcal} / \mathrm{mol})$ and binding affinity score $(-47.869 \mathrm{kcal} / \mathrm{mol})$. Analysis of the docked complex showed that the residues Ser 180, Trp 170, Ser 169 and Asp 168 (2) were involved in hydrogen bonding with Chlorogenic acid. The residue Lys 173 was involved in hydration site with the ligand Figure 2a.

\section{Trifluridine}

Trifluridine had the second-best Glide G score $(-5.417 \mathrm{kcal} / \mathrm{mol})$ and binding affinity score $(-46.574 \mathrm{kcal} / \mathrm{mol})$. Analysis of the docked complex showed that the residues Trp 170 and Asp168 were involved in hydrogen bonding with Trifluridine Figure $2 \mathrm{~b}$.

\section{Ellagic acid}

Ellagic acid had the third best binding affinity score $(-43.796 \mathrm{kcal} / \mathrm{mol})$ with Glide G score of $-4.805 \mathrm{kcal} / \mathrm{mol}$. Analysis of the docked complex showed that the residues Ser 180 (2), Lys 173 and Asp 168 were involved in hydrogen bonding with Ellagic acid Figure 2c.

\section{Kaempferol}

Kaempferol had the fourth best binding affinity score $(-41.101 \mathrm{kcal} / \mathrm{mol})$ with Glide G score of $-4.456 \mathrm{kcal} / \mathrm{mol}$. Analysis of the docked complex

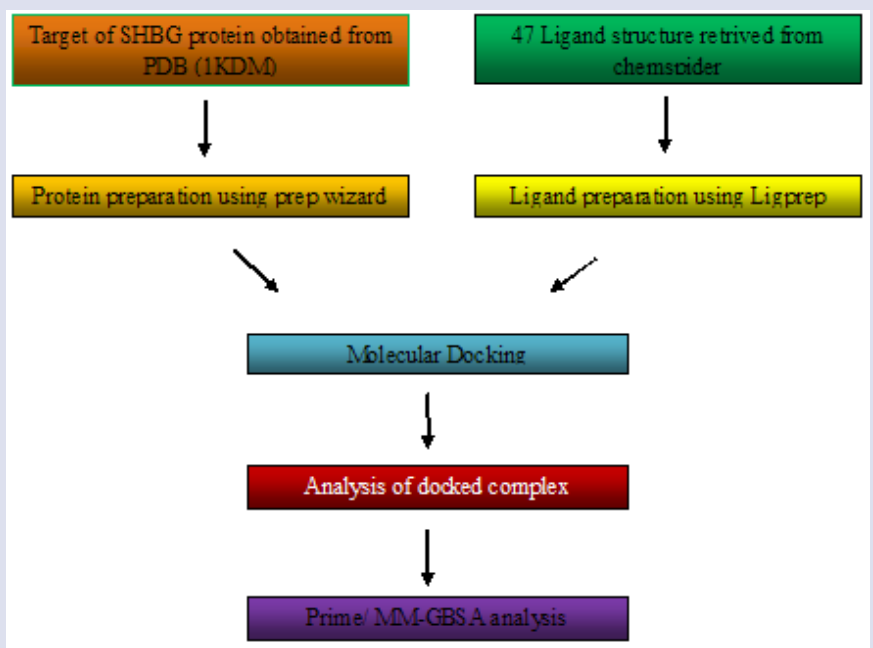

Figure 1: Schematic representation of the docking procedure and analysis.
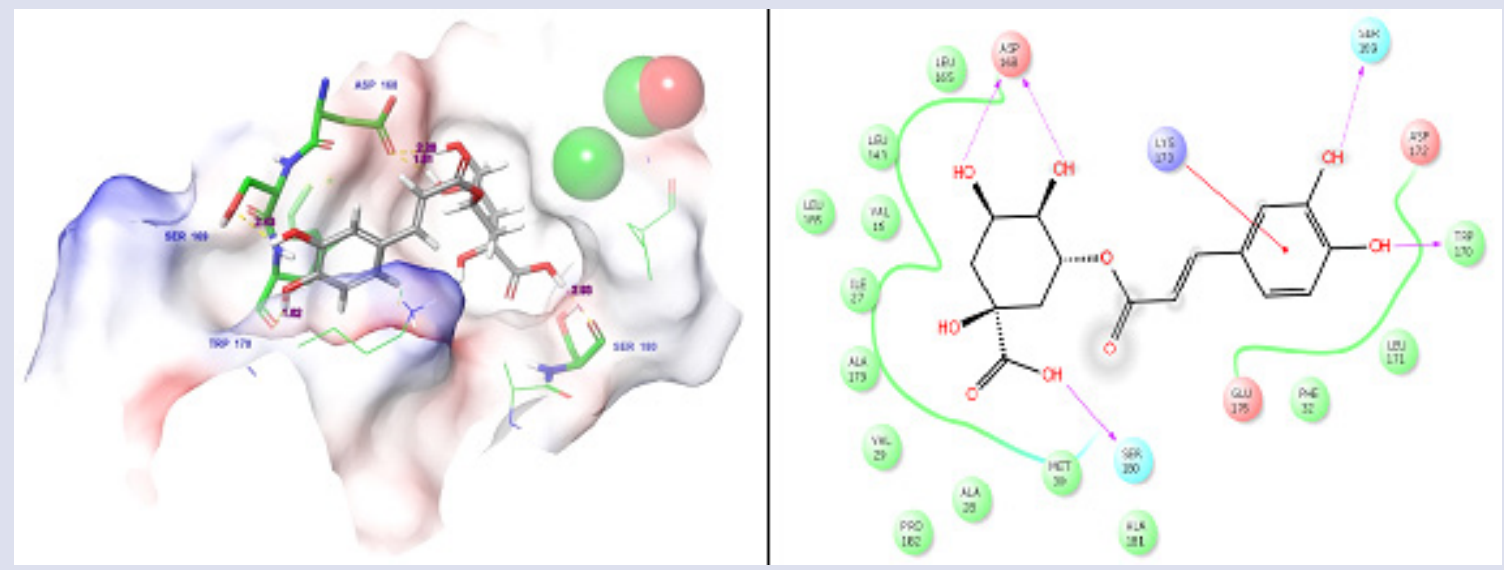

Figure 2a: Docked complex of 1KDM and Chlorogenic acid. (a). Dashed yellow line indicated hydrogen interaction $\mathrm{n}$ between target residues as well as ligand. (b). Structural view; blue solid straight line represented hydrogen bond back chain and blue dotted lines represented hydrogen bond side chain. Red colour indicated that ligand salt bridge interaction.

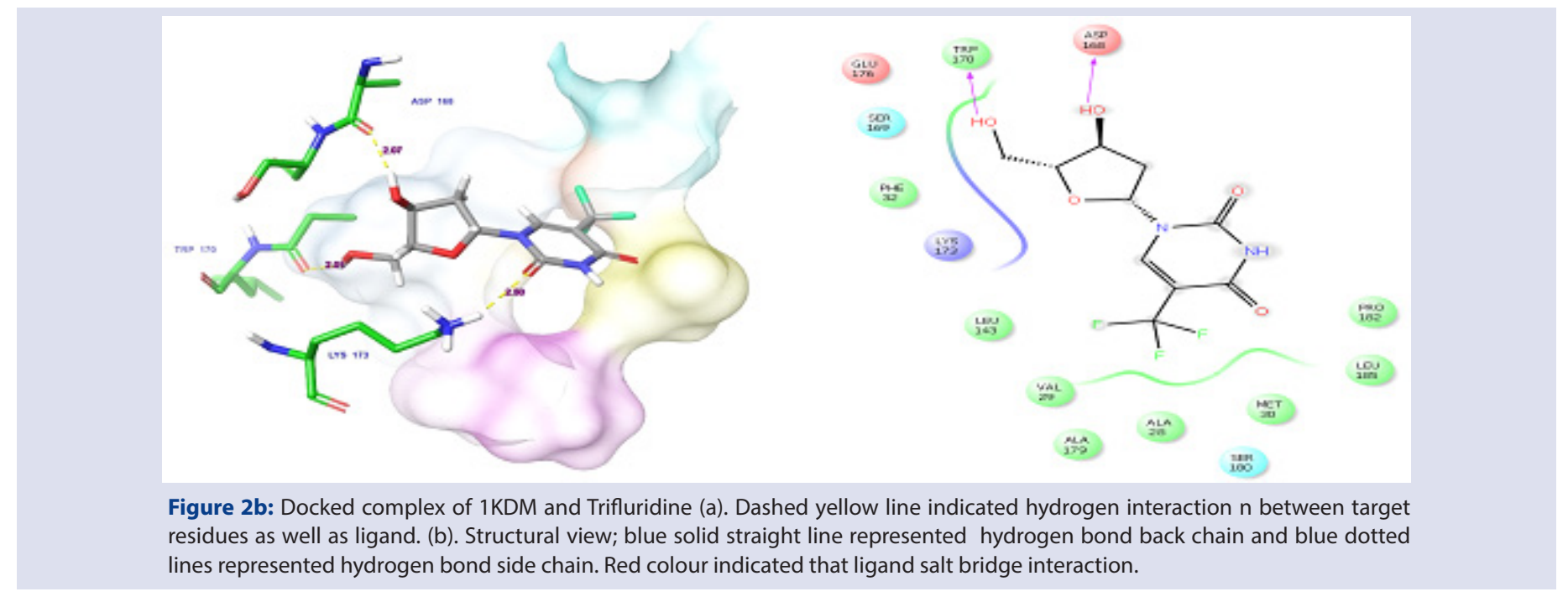



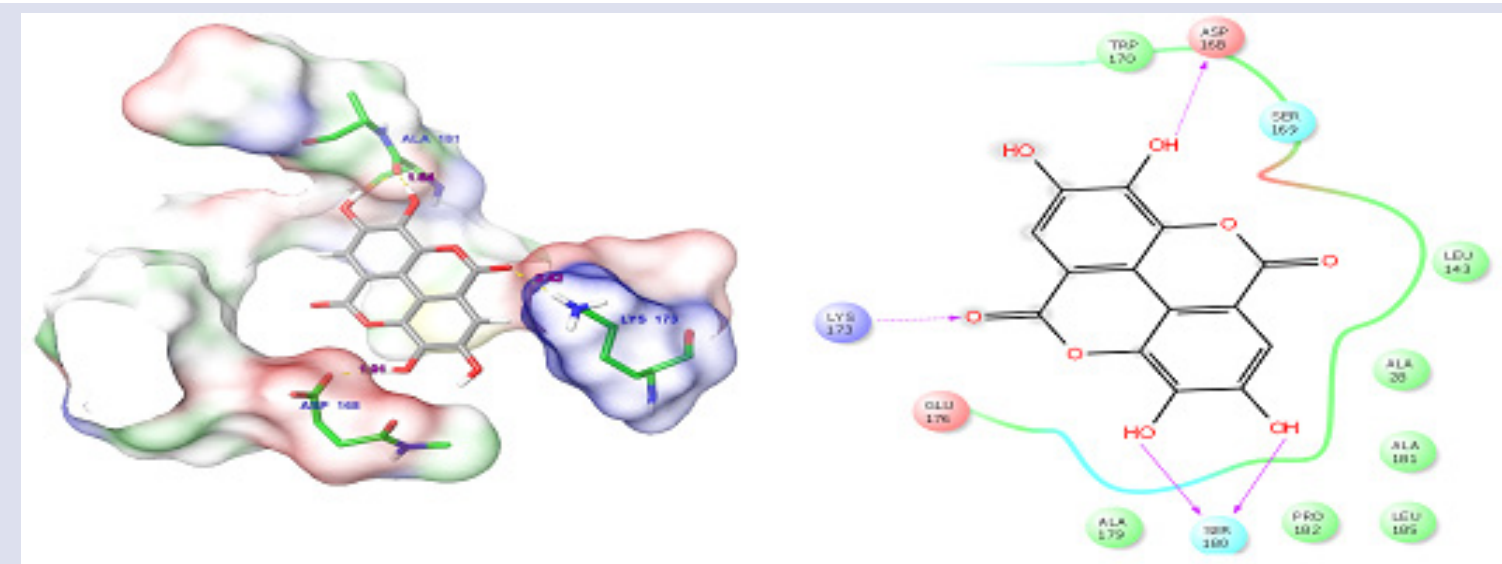

Figure 2c: Docked complex of 1KDM and Ellagic acid (a). Dashed yellow line indicated hydrogen interaction $\mathrm{n}$ between target residues as well as ligand. (b). Structural view; blue solid straight line represented hydrogen bond back chain and blue dotted lines represented hydrogen bond side chain. Red colour indicated that ligand salt bridge interaction.
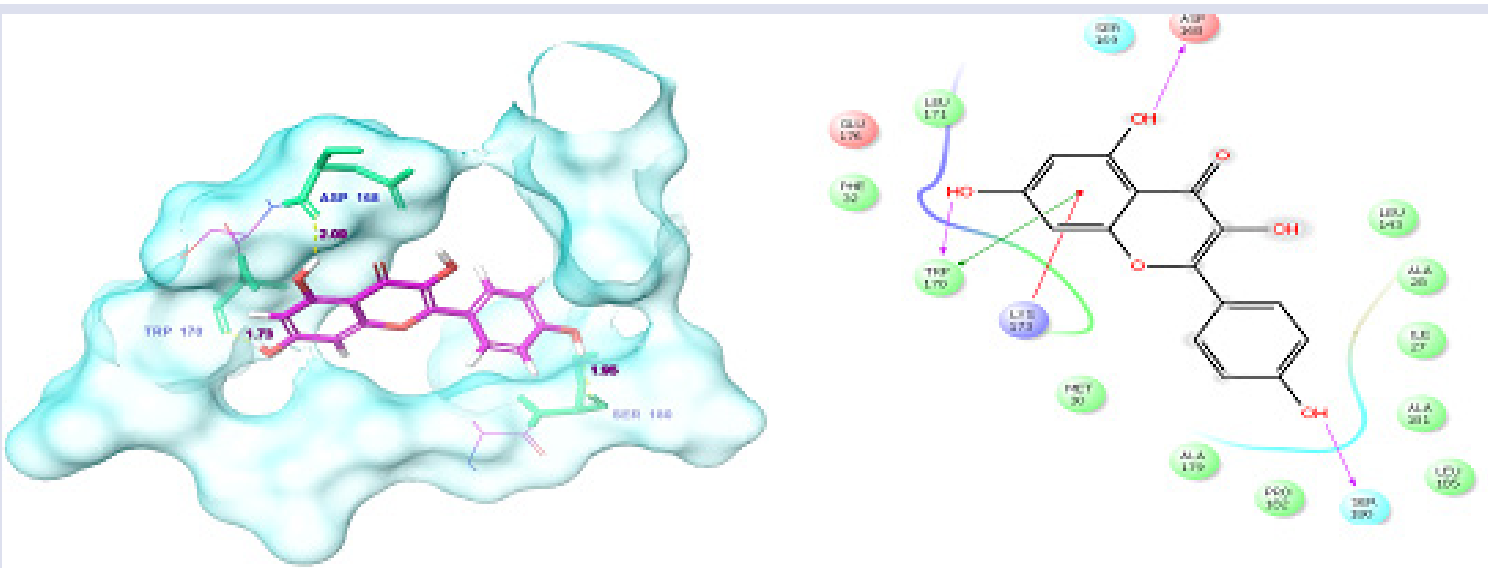

Figure 2d: Docked complex of 1KDM and Kaempferol (a). Dashed yellow line indicated hydrogen interaction $\mathrm{n}$ between target residues as well as ligand. (b). Structural view; blue solid straight line represented hydrogen bond back chain and blue dotted lines represented hydrogen bond side chain. Red colour indicated that ligand salt bridge interaction.
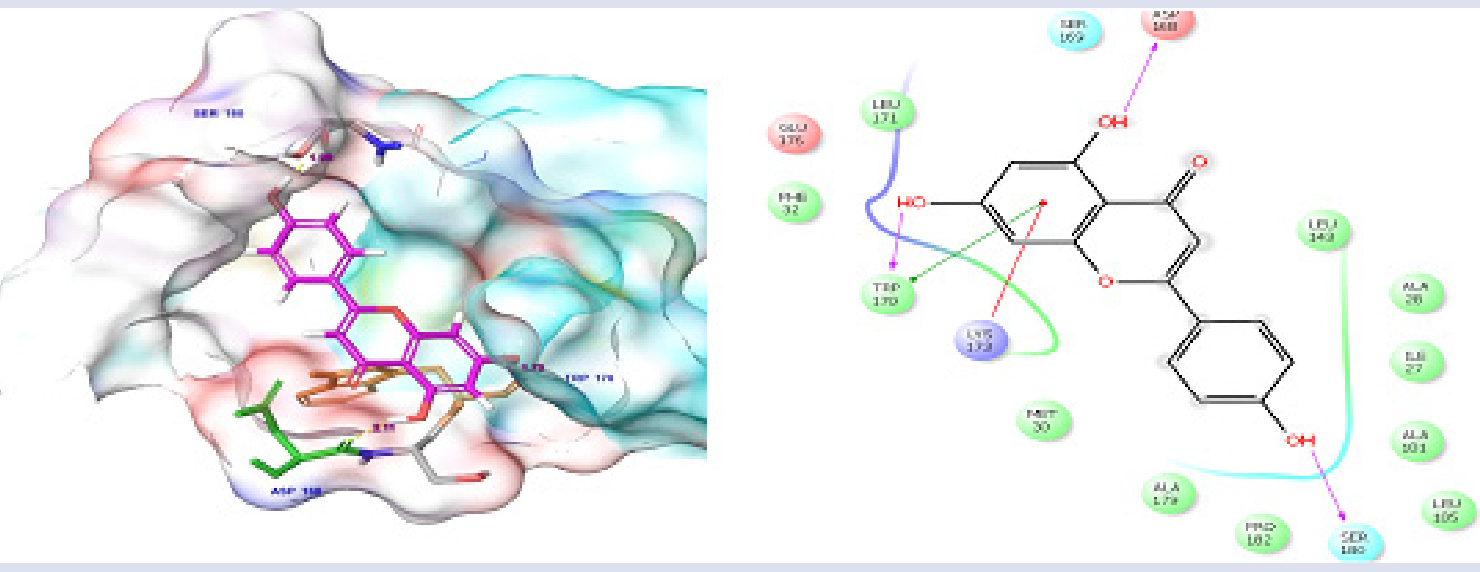

Figure 2e: Docked complex of 1KDM and Apigenin (a). Dashed yellow line indicated hydrogen interaction $n$ between target residues as well as ligand. (b). Structural view; blue solid straight line represented hydrogen bond back chain and blue dotted lines represented hydrogen bond side chain. Red colour indicated that ligand salt bridge interaction.

showed that the residues Trp 170 (2), Asp 168 and Ser 180 were involved in hydrogen bonding with Kaempferol Figure 2d.

\section{Apigenin}

Apigenin had the second-best Glide G score $(-4.149 \mathrm{kcal} / \mathrm{mol})$ and binding affinity score $(-32.849 \mathrm{kcal} / \mathrm{mol})$. Analysis of the docked complex showed that the residues Sre 180, Lys 173, Trp 170, Asp168 were involved in hydrogen bonding with Apigenin Figure 2e.

\section{Cinnamic acid}

Cinnamic acid had the fourth best binding affinity score $(-25.037 \mathrm{kcal} / \mathrm{mol})$ with Glide G score of $-3.658 \mathrm{kcal} / \mathrm{mol}$. Analysis of the docked complex 
Table 1: List of bioactive molecules and their source medicinal plants

\begin{tabular}{|c|c|c|c|}
\hline S.No. & Compounds & Plant & Reference \\
\hline 1. & Chlorogenic acid & Hibiscus sabadriffa & {$[12]$} \\
\hline 2. & Trifluridine & Calophyllum lanigerum & [13] \\
\hline 3. & Ellagic acid & Punica granatum & [14] \\
\hline 4. & Kaempferol & Moringa olifera & [15] \\
\hline 5. & Apigenin & Hibiscus rosa-sinensis & [16] \\
\hline 6. & Cinnamic acid & Glycine maxs & [17] \\
\hline 7. & Pseudotropine & Atropa belladonna & {$[18]$} \\
\hline 8. & Scopoletin & Euphorbia hirta & [19] \\
\hline 9. & Rosmarinic acid & Ocimum sanctums & [20] \\
\hline 10. & 2,2,4- Trimethyl 3-pentanone & Hibiscus rosa-sinensis & [21] \\
\hline 11. & 5-hydroxy-7, 8-dimethoxyflavanone & Andrographis paniculata & [22] \\
\hline 12. & 5, 3'-dihydroxy-7, 8, 4'-trimethoxyflavone & Andrographis paniculata & [22] \\
\hline 13. & Urosolic acid & Ocimum sanctum & [20] \\
\hline 14. & Andrographidine & Andrographis paniculata & [22] \\
\hline 15. & gallic acids & Punica granatum & [23] \\
\hline 16. & Astringent & Asparagus racemosus & [24] \\
\hline 17. & Punicalagin & Punica granatum & [23] \\
\hline 18. & Cyanidin & Hibiscus rosasinensis & [25] \\
\hline 19. & 2,6-Diisopropylnapthalene & Euphorbia golondrina & [26] \\
\hline 20. & Caffeic acid & Syzygium caryophyllatum & [27] \\
\hline 21. & Carvacrol & Ocimum sanctums & [20] \\
\hline 22. & Luteolin & Euphorbia hirta & [19] \\
\hline 23. & Linoleic acid & Syzygium caryophyllatum & [27] \\
\hline 24. & Linalool & Ocimum sanctums & [20] \\
\hline 25. & Gallic acid & Hibiscus sabdariffa & {$[12]$} \\
\hline 26. & Eucalyptol & Euphorbia golondrina & [26] \\
\hline 27. & Amylnitrite & Hibiscus rosa-sinensis & [21] \\
\hline 28. & Proline & Hybanthus enneaspermus & [28] \\
\hline 29. & Caryophyllene & Euphorbia golondrina & [26] \\
\hline 30. & 4-Pentadecyne & Ancistrocladus uncinatus & [29] \\
\hline 31. & Myricetin & Hibiscus sabdariffa & {$[12]$} \\
\hline 32. & 1 - iodoundecane & Hibiscus rosa-sinensis & {$[21]$} \\
\hline 33. & 3,6-Octadien-1-ol,3,7-dimethy & Ancistrocladus uncinatus & [29] \\
\hline 34. & 5-Caffeoylquinic acid & Hibiscus sabdariffa & {$[12]$} \\
\hline 35. & Octadecanoic acid & Ancistrocladus uncinatus & [29] \\
\hline 36. & 2-Cyclopentylethanol & Hibiscus rosa-sinensis & {$[21]$} \\
\hline 37. & 7-Tetradecenal & Ancistrocladus uncinatus & [29] \\
\hline 38. & Pinocembrin & Euphorbia hirta & [19] \\
\hline 39. & Ferulic acid & Syzygium caryophyllatum & [27] \\
\hline 40. & Quercetin & Hibiscus sabdariffa & {$[12]$} \\
\hline 41. & 1-Fluorononane & Ancistrocladus uncinatus & [29] \\
\hline 42. & riboflavin & Hibiscus rosasinensis & {$[30]$} \\
\hline 43. & Xanthotoxol & Syzygium caryophyllatum & {$[27]$} \\
\hline 44. & Bartolome & Ananas comosus & {$[31]$} \\
\hline 45. & Quercetin & Hibiscus rosa-sinensis & {$[16]$} \\
\hline 46. & Caffeic acid & Hibiscus sabdariffa & {$[12]$} \\
\hline 47. & scoparone & Euphorbia hirta & {$[19]$} \\
\hline
\end{tabular}



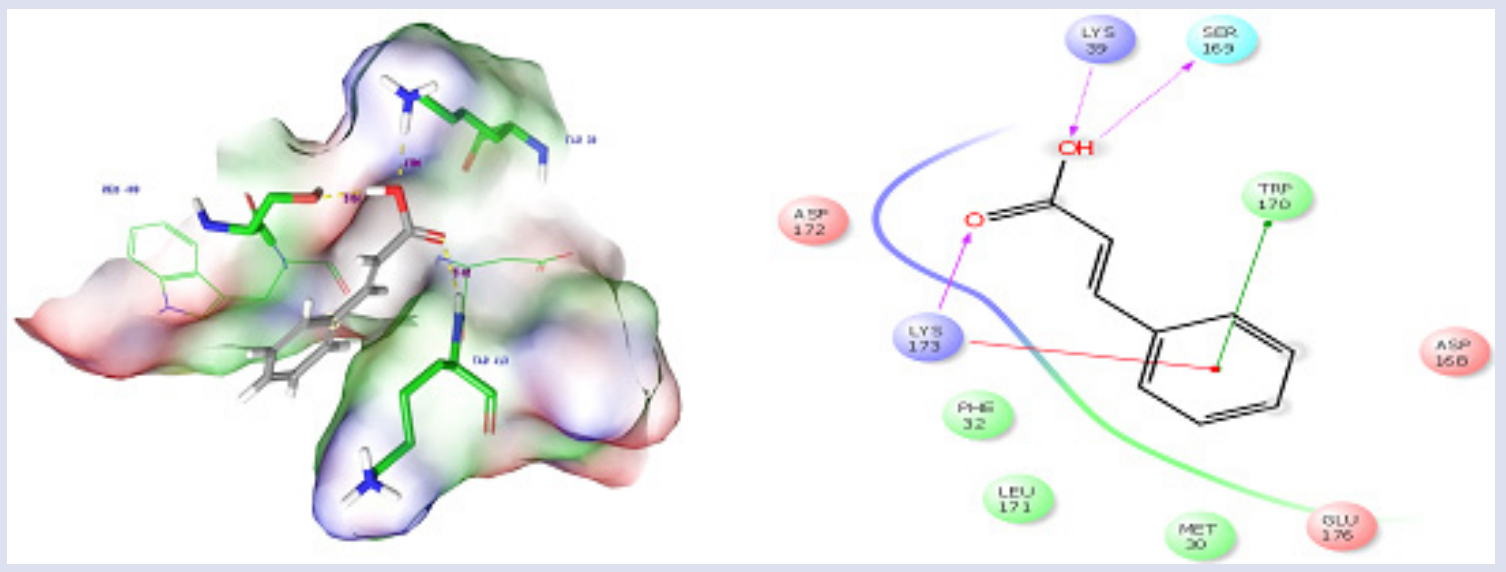

Figure 2f: Docked complex of 1KDM and Cinnamic acid (a). Dashed yellow line indicated hydrogen interaction $\mathrm{n}$ between target residues as well as ligand. (b). Structural view; blue solid straight line represented hydrogen bond back chain and blue dotted lines represented hydrogen bond side chain. Red colour indicated that ligand salt bridge interaction.

Table 2: Extra Precision Glide docking results with interacting amino acids in the active of SHBG

\begin{tabular}{cccccccc}
\hline S.No. & $\begin{array}{c}\text { Compound } \\
\text { ID }\end{array}$ & $\begin{array}{c}\text { Glide XP } \\
\text { Docking } \\
\text { score }\end{array}$ & $\begin{array}{c}\text { Glide XP } \\
\text { Energy } \\
(\mathrm{kcal} / \mathrm{mol})\end{array}$ & $\begin{array}{c}\text { Glide XP } \\
\text { Emodel }\end{array}$ & $\begin{array}{c}\text { MMGBSA dG Bind } \\
(\mathrm{kcal} / \mathrm{mol})\end{array}$ & $\begin{array}{c}\text { Interacting } \\
\text { amino acids with distance }{ }^{\text {a }}\end{array}$ \\
\hline 1. & 1405788 & -7.225 & -43.783 & -60.108 & -47.869 & Ser 180 (1.99), Ser 169 (2.43), Trp 170 (1.96), Asp 168 \\
& & & & & $-3.28)$ and Asp 168 (1.81) \\
2. & 6020 & -5.417 & -31.783 & -36.669 & -46.574 & Trp 170 (2.01), Asp (2.07) \\
3. & 4445149 & -4.805 & -34.388 & -42.045 & -43.796 & -1.2 \\
4. & 4444395 & -4.456 & -34.046 & -44.274 & -41.101 & Ser 180, Ser 180, Lys 173 and Asp 168 \\
5. & 4444100 & -4.149 & -32.849 & -41.748 & -38.841 & Ser 180, Lys 173, Trp 170, Asp 168 \\
6. & 8454 & -3.658 & -25.037 & -32.715 & -30.512 & Ser 180, Lys 173, Trp 170, Asp 168 & -1.2 \\
\hline
\end{tabular}

${ }^{a}$ Residues involved in the Docking against SHBG receptor \{the distance between the amino acid and ligand are calculated in Angstrom $(\AA)$ \}.

Table 3: Qikprop Property of natural phytocompounds representatives

\begin{tabular}{ccccccccc}
\hline S.No. & $\begin{array}{c}\text { Molecular } \\
\text { Weight Da }\end{array}$ & Volume & SASA & $\begin{array}{c}\text { Acceptor } \\
\text { HB Groups }\end{array}$ & $\begin{array}{c}\text { Donor HB } \\
\text { Groups }\end{array}$ & $\begin{array}{c}\text { Number of } \\
\text { Ring Atoms }\end{array}$ & $\begin{array}{c}\text { QPlogPw } \\
(-2 \text { to 6.5) }\end{array}$ & $\begin{array}{c}\% \text { Human Oral } \\
\text { absorption }\end{array}$ \\
\hline 1. & 354.313 & 1016.673 & 576.52 & 9.65 & 6 & 12 & 20.326 \\
2. & 296.203 & 803.413 & 485.172 & 8.6 & 3 & 11 & 14.743 \\
3. & 302.197 & 771.185 & 455.237 & 8 & 4 & 3 & 16.767 & 2 \\
4. & 286.24 & 843.244 & 504.763 & 4.5 & 3 & 16 & 12.311 \\
5. & 270.241 & 825.673 & 496.62 & 3.75 & 2 & 16 & 10.254 \\
6. & 148.161 & 565.799 & 366.827 & 2 & 1 & 6 & 3 \\
\hline
\end{tabular}

showed that the residues Lys 173, Trp 170, Ser 169, Lys 39 were involved in hydrogen bonding with Cinnamic acid Figure $2 \mathrm{f}$.

\section{Molecular dynamics simulations}

The molecular dynamics simulation was carried out for the protein SHBG and chlorogenic acid. For evaluate the structural constancy of those molecules with the help of Desmond. The final trajectory files were taken for calculating the RMSD of the complex structures. At the same time as running MD simulation for SHBG protein and chlorogenic acid for $10 \mathrm{~ns}$, the RMSD (Root Mean Square Deviation) plot shows the stability of the complex structures. The period and the constant potential energy stable at $1.2 \mathrm{~ns}$ to $10 \mathrm{~ns}$. In addition, when performing the simulation for $10 \mathrm{~ns}$, and it makes the stability of the complex structure during the entire simulation time up to 10 ns Figure 3.

\section{ADMET profiling}

In the beginning stage of drug discovery physico-chemical indicators were used to find the vital properties affecting the biological functions (ADME) Table 3. There are some important measured physico-chemical properties such as permeability, solubility, lipophilicity, integrity and stability. ${ }^{52}$ But the concept of ADME has been expanded by toxicity. ${ }^{53}$ At the initial stage of drug discovery not only the several end points related to potential hazardous effects. Right from the beginning of disclosure strategy has been utilized to give a precise expectation of pharmacokinetic properties for moment ADMET. ${ }^{54}$

\section{DISCUSSION}

Similarly, Ishfaq et al..$^{55}$ reported that the compound dimethyl phthalate is shown superior docking score with the target of SHBG. Earlier, many 


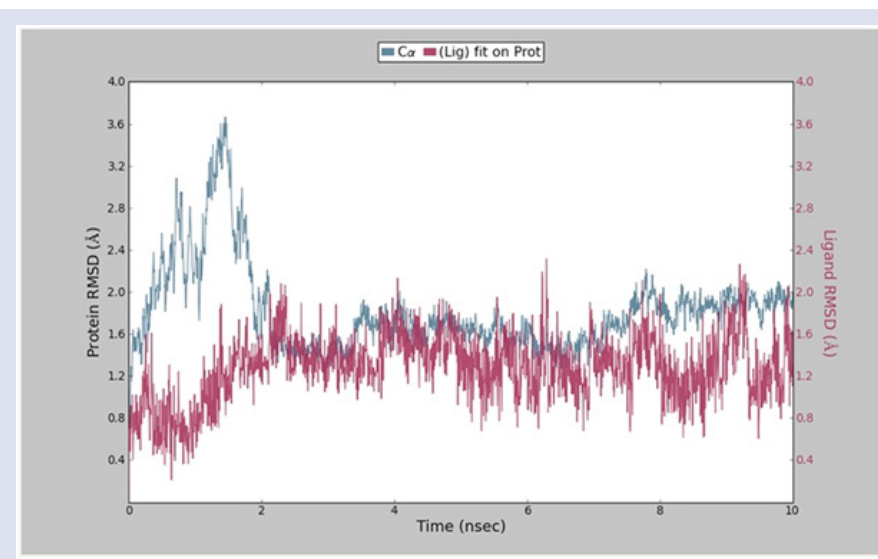

Figure 3: The root mean square deviation (RMSD) is used to measure the average change in displacement of a selection of atoms for a particular frame with respect to a reference frame. It is calculated for all frame in the trajectories.

researchers have been analyzed this molecular docking to different disease-causing receptor proteins to predicting various bioactive molecules respectively ${ }^{56,57}$. End of the outcome validation all the phytocompounds were validated by the binding mode of the target. The suitable ligand molecules have filtered based on the binding affinities of ligand to target amino acid residues. Binding affinities shows the contribution of ligand from target and strongly rely on the flexibility of receptor.

\section{CONCLUSION}

As a result of this computational experiment Phytocompound of the Chlorogenic acid has shown efficient docking score and effective binding affinities. Hence, we concluded that the chlorogenic acid may be a suitable potential to the SHBG stimulation. Based on this finding, we suggested that chlorogenic acid bioactive molecule used for further drug development process. And, this study will be addressed to further drug processing analysis.

\section{ACKNOWLEDGEMENT}

The authors are grateful to the DST-SERB (SB/YS/LS-109/2014) for providing financial assistance for this project. We specially express our thanks to the management of A.V.V.M. Sri Pushpam College (Autonomous), Poondi, for providing us necessary facilities and for supporting us to carry out this work

\section{REFERENCES}

1. Telefo PB, Lienoua LL, Yemelea MD, Lemfacka MC, Mouokeua C, Gokaa CS, et al. Ethnopharmacological survey of plants used for the treatment of female infertility in Baham, Cameroon. J Ethnopharmacology. 2011;136(1):178-87.

2. Deka J, Kalita JC. Ethnobotanical important medicinal plants of Kamrup district, Assam, India used in fertility treatment. Inter Res J Pharm. 2013;4(4):1-4.

3. Nath S, Deb B. Survey on the effect of plant extract on reproductive parameters of mammals: A review. Inter J Pure App Bioscience. 2015;3(3):216-23.

4. Vos MJ, Mijnhout GS, Rondeel JMM, Baron W, Groeneveld PHP. Sex Hormone Binding Globulin Deficiency Due to a Homozygous Missense Mutation. J Clinical Endocrinol Metabolism. 2014;99(9):1798-802.

5. Safarinejad MR, Shafiei N, Safarinejad S. Association of the (Thymine Adenine Adenine Adenine Adenine)n repeat and Asp327Asn polymorphisms in the sex hormone-binding globulin (SHBG) gene with idiopathic male infertility and relation to serum Sex Hormone Binding Globulin concentrations. J Steroid Biochemist Molecular Bio. 2011;123(1):37-45

6. Artem C, Zheng S, Magid F, Geoffrey LH. Successful in Silico Discovery of Novel Nonsteroidal Ligands for Human Sex Hormone Binding Globulin. J Med Chemistry. 2005;48(9):3203-13.

7. Hong $\mathrm{H}$, Branham WS, Ng HW, Moland CL, Dial SL, Fang H, et al. Human
Sex Hormone Binding Globulin Binding Affinities of 125 Structurally Diverse Chemicals and Comparison with Their Binding to Androgen Receptor, Estrogen Receptor and $\alpha$-Fetoprotein. Toxicological Sci. 2015;143(2):333-48.

8. Sheikh IA, Turki RF, Abuzenadah AM, Damanhouri GA, Beg MA. Endocrine Disruption: Computational Perspectives on Human Sex Hormone-Binding Globulin and Phthalate Plasticizers. Plos one. 2016;11(3):1-13.

9. Safarinejad MR. Effect of omega-3 polyunsaturated fatty acid supplementation on semen profile and enzymatic anti-oxidant capacity of seminal plasma in infertile men with idiopathic oligoasthenoteratospermia: a double-blind, placebo-controlled, randomized study. Andrologia. 2011;43(1):38-47.

10. Schrodinger, LLC, New York, NY. 2014.

11. Elbegdorj O, Westkaemper RB, Zhang Y. A homology modeling study toward the understanding of three-dimensional structure and putative pharmacological profile of the G-protein coupled receptor G-protein-coupled receptor-55. J Molecular Graphics Model. 2013;39:50-60.

12. Rocha IDC, Bonnlaender B, Sievers H, Pischel I, Heinrich M. Hibiscus sabdariffa L. - A phytochemical and pharmacological review. Food Chemistry. 2014;165:424-43.

13. Upadhyay RK. Plant latex: A natural source of pharmaceuticals and pesticides. International Journal of Green Pharmacy 2011:5(3):169-80.

14. Mohammad SM, Kashani HH. Chemical composition of the plant Punica granatum L. (Pomegranate) and its effect on heart and cancer. $J$ of Med Plants Res. 2012;6(40):5306-10.

15. Tejas HG, Umang HJ, Payal NB, Tusharbindu RD, Pravin RT. A Panoramic View on Pharmacognostic, Pharmacological, Nutritional Therapeutic and Prophylactic Values of Moringa Oleifera Lam. Inter Res J Pharm. 2012;3(6):1-7.

16. Salib JY, Daniel EN, Hifnawy MS, Azzam SM, Shaheed IB, Abdel-Latif SM. Polyphenolic compounds from flowers of Hibiscus rosa-sinensis Linn. and their inhibitory effect on alkaline phosphatase enzyme activity in vitro. Z Naturforschung C. 2011;66(9-10):453-9.

17. Salvador VH, Lima RB, Santos WD, Soares AR, Böhm PAF, Marchiosi R, et al. Cinnamic Acid Increases Lignin Production and Inhibits Soybean Root Growth. Plos one. 2013;8(7): e69105. doi:10.1371/journal.pone.0069105.

18. Rothe G, Hachiya A, Yamada Y, Hashimoto T, Drager B. Alkaloids in plants and root cultures of Atropa belladonna over expressing putrescine N -methyltransferase, J Experimen Bot. 2003;54(390):2065-70.

19. Wu Y, Qu W, Geng D, Liang JY, Luo YL. Phenols and flavonoids from the aerial part of Euphorbia hirta. Chin J Nat Med. 2012:10(1):40-2.

20. Pattanayak P, Behera P, Das D, Panda SK, Ocimum sanctum Linn. A reservoir plant for therapeutic applications: An overview, Pharmacognosy Rev. 2010; 4(7):95-105

21. Agarwal S, Prakash R. Essential Oil Composition of Solvent Extract of Hibiscus rosa-sinensis Flower. Ultra Chem. 2013;9:178-9.

22. Xu C, Wang ZT. Chemical constituents from roots of Andrographis paniculate. Yao Xue Xue Bao. 2011;46(3):317-21.

23. Amani SAR, Edwards G, Al-Sibani M, Al-Thani G, Ahmed S, Al-Harrasi, et al. Phenolic Constituents of Pomegranate Peels (Punica granatum L) Cultivated in Oman, Europe J Med Plan. 2014;4:315-31.

24. Negi JS, Singh P, Joshi GP, Rawat MS, Bisht VK, Chemical constituents of Asparagus. Pharmacognosy Rev. 2010;4(8):215-20.

25. Ruban P, Gajalakshmi K. In vitro antibacterial activity of Hibiscus rosasinensis flower extract against human pathogens. Asian Pac J Trop Biomed. 2012;2(5):399-403.

26. Ndam LM, Mih AM, Tening AS, Fongod AGN, Temenu NA, Fujii Y. Phytochemical analysis, antimicrobial and antioxidant activities of Euphorbia golondrina LC. Wheeler (Euphorbiaceae Juss.): an unexplored medicinal herb reported from Cameroon. Springer plus. 2016;5(1). doi:10.1186/s40064-016-1928-8.

27. Kala K, Antony VT, Sheemole MS, Saji A. Analysis of Bioactive Compounds Present in Syzygium caryophyllatum (L). Alston Fruit. Inter J Pharm Sci Rev Res. 2016;36:239-43.

28. Rex D, Ragavan. Studies on Phytochemicals, Antioxidant and Cytotoxicity Effect of Hybanthus Enneaspermus. Inter J Pharm Pharmaceutical Sci. 2014:6(6) 567-572.

29. Fasina FO, Olaokun OO, Olusola OO, Margaret MF, Adesoji AM, Livio H, et al. Phytochemical analysis and in-vitro anti-African swine fever virus activity of extracts and fractions of Ancistrocladus uncinatus, Hutch and Dalziel (Ancistrocladaceae). BioMed Central Vet Res. 2013:9(1):1-11.

30. Divya MJ, Sowmia C, Dhanya KP, Joona K. Screening of Antioxidant, Anticancer Activity and Phytochemicals in Methanolic Extract of Hibiscus-rosa-Sinensis Leaf Extract. Res J Pharma Bio Chemist Sci. 2013:4(2) 1308-1316.

31. Pardo MS, Ramos-Cassellis ME, Escobedo RM, Garcia EJ. Chemical Characterization of the Industrial Residues of the Pineapple (Ananas comosus). J Agric Chemist Environ. 2014:3(2):53-56.

32. (http://www.chemspider.com)

33. (http://www.rcsb.org/pdb/home/home.do).

34. Santiago V, Giulio F, Sharangdhar SP, Barkin B, Claudio NC, Stefano C. Dockingbased virtual screening for ligands of $\mathrm{G}$ protein-coupled receptors: Not only crystal structures but also in silico models. J Molecular Graphics Model. 
$2011 ; 29(5): 614-23$

35. Thorsteinson N, Ban F, Santos-Filho O, Tabaei, SMH, Miguel-Queralt S, et al. In silico identification of anthropogenic chemicals as ligands of zebrafish sex hormone binding globulin. Toxicology Applied Pharm. 2009;234(1):47-57.

36. LigPrep, 2011.Version2.5, Schrödinger, LLC, New York.

37. Glide, 2011.version5.7, Schrödinger, LLC, New York

38. MaulanaT, Hari P.Tea leaves extracted as anti-malaria based on molecular docking plants. Proc Environ Sci. 2013;17:188-94.

39. Ramachandran B, Kesavan S, Rajkumar T. Molecular modeling and docking of small molecule inhibitors against NIMA-related kinase 2. Bioinformation. 2016;12(2):62-8.

40. Vilar S, Ferinoa G, Phatak SS, Berka B, Cavasottob CN, Costanzia S. Docking based virtual screening for ligands of $G$ protein-coupled receptors: Not only crystal structures but also in silico models. J Molecular Graph Model. 2011;29(5):614-23.

41. Salameh BA, Cumpstey I, Sundin A, Leffler, Nilsson UJ. 1H-1, 2,3-triazol-1-yl Thiodigalactoside derivatives as high affinity galectin-3 inhibitors. Bioorganic Med Chem. 2010;18(14):5367-78.

42. Aathi M, Piramanayagam S. In silico validation of human N-myc downstreamregulated gene 2 protein against Alzheimer's disease using molecular modeling, docking and dynamics studies. Drug invent today. 2013;5(1):22-7.

43. Baig MH, Sudhakar DR, Kalaiarasan P, Subbarao N, Wadhawa G, Lohani M, et al. Insight into the Effect of Inhibitor Resistant S130G Mutant on Physico-Chemical Properties of SHV Type Beta-Lactamase: A Molecular Dynamics Study. Plos one. 2014; 9(12): doi:10.1371/journal.pone.0112456.

44. Mohammad HB, Khurshid A, Sudeep R, Jalaluddin MA, Mohd A, Mohammad HS, et al. Computer Aided Drug Design: Success and Limitations, Current pharma des. 2016;22(5):572-81.

45. Prime, version 3.1, Schrödinger, LLC, New York, 22 NY. 2012.

46. http://www.schrodinger.com/kb/1635,Schrodinger Prime User Manual

47. Subhani S, Archana J, Jamil K. Homology modelling and molecular docking of Multi Drug Resistance1 with chemotherapeutic agents in non-small cell lung cancer. Biomed Pharma. 2015;71:37-45.

\section{GRAPHICAL ABSTRACT}

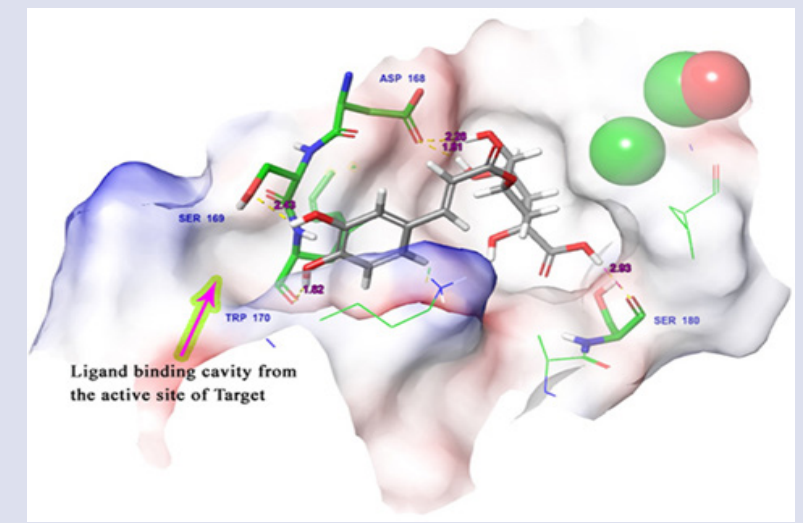

48. Mustyala K, Malkhed V, Chittireddy VR, Vuruputuri U. Virtual screening studies to identify novel inhibitors for Sigma F protein of Mycobacterium tuberculosis. Inter J Mycobacteriology. 2015;4(4):330-6.

49. Singh SP, Gogoi B, Konwar BK, Ramteke A. Homology modelling and molecular docking studies of nitric oxide synthase (inducible) of Gallus gallus. J Pharm Res. 2013;7(5):443-7.

50. Chigurupati S, Selvaraj M, Mani V, Selvarajan KK, Mohammade JI, Kaveti B, et al. Identification of novel acetylcholinesterase inhibitors: Indolopyrazoline derivatives and molecular docking studies. Bioorganic Chem. 2016;67:9-17.

51. Zhou J, Ma HY, Fan XS, Xiao W, Wang TJ. Molecular docking of chlorogenic acid, 3, 4-di-O-caffeoylquinic acid and 3, 5-di-O-caffeoylquinic acid with human serum albumin. J Chin Inter Med. 2012;10(10):1149-54.

52. Roy S, Kumar A, Baig MH, Masarik M, Provaznik I. Virtual screening, ADMET profiling, molecular docking and dynamics approaches to search for potent selective natural molecules based inhibitors against metallothionein-III to study Alzheimer's disease. Meth 2015;83:105:10.

53. Ishfaq AS, Rola FT, Adel MA, Ghazi AD, Mohd AB. Endocrine Disruption: Computational Perspectives on Human Sex Hormone-Binding Globulin and Phthalate Plasticizers. plos one. 2016;11(3):1-13.

54. Ruggiero MA, Gordon DP, Orrell TM, Bailly N, Bourgoin T. Correction: A HigherLevel Classification of All Living Organisms. Plos one. 2015;10(6):e0130114. doi: 10.1371/journal.pone.0130114

55. Jorgensen RA, Cluster PD, English JJ, Que Q, Napoli CA. Chalcone synthase co-suppression phenotypes in petunia flowers: comparison of sense vs. antisense constructs and single-copy vs. complex T-DNA sequences. Plant Mole Biol. 1996; $31(5): 957-73$.

56. Kraft NJB, Comita LS, Chase JM, Sanders NJ, Swenson NG, Crist TO, et al. Disentangling the drivers of beta diversity along latitudinal and elevational gradients. Sci. 2011;333(6050):1755-8.

57. Kaminski M, Ding M, Truccolo W, Bressler SL. Evaluating causal relations in neural systems: Granger causality, directed transfer function and statistical assessment of significance. Biological Cybernet. 2001;85(2):145-57.

\section{SUMMARY}

- Sex Hormone Binding Globulin (SHBG) is involved to binds the androgens and estrogens in mammalian. It plays very essential role to safeguard the sex steroids between bound and unbound. Generally, the male infertility affects one in six couple in world which holds up with the development of spermatogenesis and it decreases the quality and quantity of sperm production. Commonly, people are spoiled their sperm production capacity especially male by the reason of certain mental and physiological illnesses which includes coronary heart disease, diabetes, chronic disease, etc. Spermatogenesis also caused by some genetic factors. Traditionally, the medicinal plants are having lots active primary and secondary metabolites which also act as physiological function into the human body especially reproductive system in both male and female.

\section{ABOUT AUTHORS}

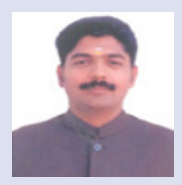

Dr. S. Vijayakumar has received his doctorate degree from Barathidhasan University and has more than 15years of teaching experience at U.G. and P.G. levels. He has 15 years of research experience. He is workingas Assistant Professor in the Department of Botany and Microbiology, A.V.V.M. Sri Pushpam College (Autonomous),Poondi-613 503, Thanjavur district, Tamil Nadu. He has got vast experience in research especially oncyanobacteria, Medicinal plants, Environmental Microbiology and Computer Aided Drug Design (CADD). He has guided P.G. students for their projects in the field of fresh water Algae, Medicinal plants and Bioremediation. At present he is completed $10 \mathrm{Ph} . \mathrm{D}$ and guiding 8 Ph.D. programme in this line. So, far he has guided $22 \mathrm{M}$. Phil.,candidate for their degree and published 68 research papers in the SCl journals. He has got best paper award from National Symposium on "Algae, Man and Biosphere" and International Medicinal Plants and Pharmacological Research, Columbo University, Srilanka. Recently, he got YOUNG SCIENTIST AWARD from Wasinghton University, USA. He has visited more than 8 countries which include Spain, Dubai, Sri Lanka, Singapore, etc. He also completed One UGC Minor and UGC Major Project. Right now one DST-SERB major projectis ongoing in the area of Computer Aided Drug Design and Modelling. 
Mr. J.E.Morvinyabesh has received his under and post graduation in Botany from A.V.V.M. Sri Pushpam College. Presently, he is studying Doctor of Philosophy in Department of Botany and Microbiology at same institution under the supervision of corresponding author of this paper. Currently, he is studying about Venereal diseases and those diseases causing opportunistic pathogens. He is seeking drug efficient having medicinal plants and their bioactive molecules for curing those venereal diseases. He has also handled some advanced computational tools for identify new drug candidate.

Cite this article: Esther MJ, Subramaniyan V, Kumar AP, Subramanian M and Palani M. Molecular Docking, ADMET Analysis and Dynamics Approach to Potent Natural Inhibitors against Sex Hormone Binding Globulin in Male Infertility. Pharmacog J. 2017;9(6) Suppl:s35-s43. 